\title{
Imágenes, discursos y escándalos de corrupción. El Banco Provincial de Santa Fe, 1889-1894
}

Images, discourses and corruption scandals. The Banco Provincial de Santa Fe, 1889-1894

\author{
Romina Garcilazo \\ Universidad Nacional de Rosario, Argentina \\ romina_garcilazo@hotmail.com
}

\section{Resumen:}

El artículo analiza las imágenes y los discursos construidos por la prensa de humor político en torno a los escándalos de corrupción suscitados en el Banco Provincial de Santa Fe durante las décadas de 1880 y 1890. A partir de ciertos nudos problemáticos enmarcados en la "Nueva" Historia Cultural de la Corrupción Política, se examinan las acepciones que adquirió el término corrupción y el modo en el que fueron retratados los protagonistas de los escándalos. El principal aporte de este trabajo es reflexionar, a través de la discursividad periodística, sobre la importancia que revistieron los espacios bancarios como escenarios de prácticas de corrupción.

Palabras Clave: Escándalos, Corrupción, Prensa, Banco Provincial de Santa Fe.

\section{Abstract:}

The paper analyzes the images and discourses constructed by the political humor press about the corruption scandals aroused on the Banco Provincial de Santa Fe during the 1880s and 1890s. We examine the meanings adopted by the term corruption and the way the scandals principal actors are portayed based on certain problems framed on the "New" Cultural History of the Political Corruption. The main contribution of this paper is thinking from the journalistic discourse about the importance of the banks as scene of corruption practices.

KeYwords: Scandals, Corruption, Press, Banco Provincial de Santa Fe.

Renunció Juárez, pero quedó su sistema de gobierno (...) pero quedan sus cómplices en la ruina y la deshonra de la nación argentina, de pié todavia y tratando de defenderse de sus posiciones ¿No tenemos todos los bancos de la República fundidos, porque han desaparecido sus caudales entre unos cuantos?

(La Unión Cívica, 31/10/1890).

\section{INTRODUCCIÓN}

El parágrafo previamente citado nos introduce en una de las aristas más candentes de la década de 1890 en la Argentina: las denuncias de corrupción durante la etapa presidencial de Miguel Juárez Celman (1886-1890). Tal como lo sugiere el periódico mencionado, uno de los epicentros de las tramas vinculares entre empresariado y poder político, que derivaron en escándalos de corrupción, fueron las entidades bancarias.

En el presente artículo nos proponemos analizar los escándalos de corrupción suscitados en una de las casas bancarias provinciales más dinámicas de la época: el Banco Provincial de Santa Fe (BPSF) durante el período 1889-1894, momento en el que cobraron fuerte notoriedad pública las denuncias sobre sus irregularidades. ${ }^{1}$ Nuestro objetivo es adentrarnos en una de las temáticas que guían la "Nueva" Historia Cultural de la Corrupción Política, así como explorar las acepciones que el concepto de corrupción adquirió 
en un contexto y espacio determinado. ${ }^{2}$ Abordaremos la presente problemática a través de la llamada prensa de humor político. ${ }^{3}$ La elección se sustenta, por un lado, en el rol denuncialista que el periodismo evidenció respecto de las irregularidades administrativas circunscriptas a la esfera nacional, provincial y municipal hacia fines del siglo XIX (Dell' Acqua, 1960, pp. 20-21). Por otro, dichas fuentes adquieren una gran potencialidad investigativa, en tanto que, a partir de su prosa singular e imágenes burlescas, representaron, de manera particular, las prácticas de corrupción y los rasgos de los actores involucrados (Román, 2010, p. 7).

Si bien parte de la historiografía nacional ha abordado el fenómeno de la corrupción en la década de 1890 , focalizándose en el rol de la prensa diaria y periódica (Alonso, 2004, 2010; Giordano, 2000, 2003; Hirsch, 2012, 2013; Matallana, 1999, 2003; Rojking, 2012), el presente trabajo se propone mirar el problema desde otras aristas menos exploradas. Una de ellas, siguiendo las ideas de otros autores, es analizar las entidades bancarias como ámbitos privilegiados donde se entramaron vínculos políticos-empresariales que derivaron en denuncias de corrupción (Duncan, 1981; Lotersztain, 2010). Una segunda alude a la metodología empleada, ya que se combinan algunas de las preocupaciones que orientan la "Nueva" Historia Cultural de la Corrupción - como las acepciones del término- con los estudios circunscriptos al rol de la prensa en la difusión de dichas prácticas. Sobre este último punto, colocaremos el foco en las ideas e imágenes construidas por la discursividad periodística en torno a dicho concepto y a los actores involucrados en las denuncias (políticos, empresarios, directores de bancos y periodistas). Para ello hemos tomando como marco referencial un corpus bibliográfico específico referido a la problemática de la corrupción (Burdiel, 2018; Laporta, 1997; Monier, Dard y Engels, 2014; Little y Posada Carbó, 1996; Robotnikof, 1999; Rosenmüller y Ruderer, 2016), al rol de la prensa en este tipo de hechos (Thompson, 2001; Jiménez Sánchez, 1995, 1997; Zamora y Marín Albaladejo, 2010) y a las particularidades del periodismo de humor político en la Argentina de fines del siglo XIX (Dell'Acqua, 1960; Matallana 1999, 2003; Román, 2010; Szir, 2011, 2014).

Algunos de los interrogantes centrales del presente artículo son los siguientes: a partir del caso analizado, ¿qué acepciones revistió el concepto de corrupción en la prensa de humor político? ¿Con qué imágenes y discursos se representó dicho término? ¿Cómo fueron retratados los actores involucrados en las denuncias de corrupción?

Para el desarrollo de la investigación empleamos un corpus documental constituido por periódicos de humor político que circulaban en Rosario - ya que los acontecimientos que aquí se relatan aluden específicamente a lo ocurrido en la sucursal del BPSF en dicha ciudad-y que tuvieron un rol destacado en el desarrollo y la publicidad del conflicto, ya sea denunciando (La Cabrionera y La Bomba) o defendiendo a la entidad (Caramelo). Por otra parte, en algunos tramos del texto hemos puesto en diálogo la información publicada en la prensa local respecto de la cuestión bancaria con la difundida en el periodismo de humor porteño (El Mosquito y Don Quijote) y en el diarismo rosarino (El Municipio), con el objeto de complejizar algunas aristas del problema a tratar.

\section{Los INICIOS DE LA DÉCADA DE 1890 EN ARgENTINA: CORRUPCión Y ESCÁNDALOS DE CORRUPCIÓN}

La corrupción es uno de los fenómenos universales que ha prevalecido a lo largo del tiempo y se ha convertido en un componente no exclusivo de diferentes momentos históricos, espacio territorial o sistema político. Sin embargo, su significado ha variado según las etapas temporales y las sociedades en las que se desarrolló (Malem Seña, 1997, p. 170).

Durante la modernidad, el término estuvo asociado a la desintegración o descomposición física y moral y a la perversión de los funcionarios públicos en el ejercicio de sus tareas. Posteriormente, dicha palabra se vinculó a aquellas acciones que quebrantaban los códigos sociales normativos morales y positivos (Robotnikof, 1999, p. 26). 
Las prácticas corruptas pueden ser ignoradas, aceptadas o repudiadas por el conjunto social. En este último caso, se asocian al fenómeno del escándalo (Zamora y Marín Albaladejo, 2010, p. 5). Respecto de ello, recientemente, la historiografía ha hecho hincapié en la importancia y potencialidad de analizar la corrupción colocando especial atención en la percepción social de las prácticas. Asimismo, dichos estudios han destacado la fuerte influencia de la opinión pública en las visiones que sobre dichas prácticas construyen las distintas sociedades (Engels, 2017).

La década de 1890, que se inicia en la Argentina con una fuerte crisis económica, política y social, ha marcado un momento de inflexión en las percepciones sociales de la corrupción (Bonaudo, 2018, p. 1). Cabe recordar que, en julio de 1890, un movimiento integrado por civiles y fracciones del ejército - conocido como La Revolución del Parque- intentó derrocar al entonces presidente Juárez Celman. Los protagonistas de estas revueltas, los llamados Cívicos, se habían levantado en armas en contra de un régimen que era acusado de atentar contra la estructura institucional, el sistema normativo y las libertades públicas. Según la oposición política, tal estado de situación había convertido al gobierno nacional en un engranaje permeado de corrupción. Este último aspecto no sólo se evidenciaba en el plano político, sino también en el ámbito socioeconómico ya que el espíritu mercantil había inundado y pervertido a la sociedad en su conjunto (Rojking, 2012, p. 508; Hirsch, 2012, p. 159). Las entidades bancarias oficiales y la Bolsa de Comercio de Buenos Aires, entre otras instituciones, se erigieron como los grandes monumentos sobre los cuales se aglutinaban las prácticas más indignas.

Paralelamente a ese movimiento - que si bien fue sofocado, logró precipitar la renuncia del primer mandatario-, existió una multiplicidad de expresiones públicas que visibilizaron la necesidad de regenerar las estructuras sociales corrompidas. Algunas de ellas se exteriorizaron en el parlamento nacional, en las manifestaciones callejeras, en las reuniones políticas y por medio de la prensa y la novelística de la época (Rojking, 2012; Hirsch, 2012, 2013; Bonaudo, 2018).

También, esas críticas se extendieron a las administraciones provinciales. En 1890 en Santa Fe, y en consonancia con lo acaecido en la esfera nacional, la política provincial se vio convulsionada por la emergencia de la Unión Cívica, que tuvo importante adhesión en Rosario y en las colonias del centro-oeste provincial (Bonaudo, 2005, pp. 31- 33). Ello se explica, en parte, por la fuerte oposición al autonomismo local. Cabe recordar que el gobernador Gálvez (1886-1890) fue uno de los máximos referentes de dicha fracción política y, durante la etapa juarista, mantuvo una relación cordial con la dirigencia nacional (Alonso, 2010, pp. 238-239). ${ }^{4}$ Por aquellos años, Santa Fe se convirtió en una de las provincias más prósperas de la Argentina debido a su exitosa incorporación al modelo agroexportador, sustentado en la comercialización de carnes y cereales. Este proceso estuvo acompañado por el fuerte flujo inmigratorio - de origen europeo-, la extensión de las líneas de comunicación — terrestres y fluviales - y el crecimiento de grandes centros urbanos como Rosario, ciudad ubicada al sur provincial.

Esa etapa de prosperidad contó con el accionar del Estado provincial. Sólo para dimensionar la celeridad de estos cambios mencionamos algunos datos que resultan indicativos. Durante la década de 1880 se multiplicaron las líneas férreas, el número de colonias agrícolas, la creación de bancos y el desarrollo de las obras públicas en los principales centros urbanos de la provincia (Martirén, 2016, pp. 48-57). Pese a dichos cambios, la administración de Gálvez fue criticada desde la oposición. En esos años existió un estrecho vínculo entre la clase dirigente provincial y un conjunto de empresarios locales que derivó en ciertas prácticas que generaron una enérgica indignación social. Entre ellas se destacaban los negociados poco trasparentes en torno a la compra de tierras fiscales, las irregularidades en la ejecución de la obra pública provincial y los manejos poco claros del BPSF, entidad que tenía entre sus principales accionistas al Estado provincial (De Marco, 2002; Garcilazo, 2013, 2017a). 


\section{LOS ESCÁNDALOS DE CORRUPCIÓN EN LA PRENSA DE HUMOR POLÍTICO}

En el mundo contemporáneo, los medios de comunicación en general y la prensa en particular, debido a su capacidad de difusión, han sido una de las correas de transmisión a partir de la cual se han propagado los escándalos de corrupción (Jiménez, 1995, p. 27). En la Argentina, hacia fines de la década de 1880 y principios de la siguiente, el periodismo - fundamentalmente el asentado en la ciudad de Buenos Airesemprendió una fuerte prédica moralizadora para regenerar las tramas sociales (Hirsch, 2012, p. 161; 2013). El claro involucramiento político que la prensa opositora mostró en las denuncias contra la administración juarista quedó evidenciado en algunos hechos concretos. Uno de ellos lo constituyó ese grupo de personas que, entusiastas por la noticia del alejamiento político de Juárez Celman, acudió a los edificios de los periódicos para festejar la buena nueva (Rojkind, 2012, p. 515).

Cabe recordar que el periodismo de humor tuvo una fuerte presencia en el mundo occidental desde fines del 1700 y adquirió mayor visibilidad en el siglo siguiente. Para el caso argentino, se caracterizó como un tipo de prensa ilustrada de carácter heterogéneo por la diversidad de su iconografía, sus elementos visuales y propuestas ideológicas, políticas y estéticas. Sin embargo, la mayoría de las empresas editoriales compartían un elemento en común: su prédica política teñida de un lenguaje satírico y agresivo (Szir, 2014, pp. 82-83; Román, 2010, p. 305). Ese atributo se correspondió, por un lado, con la función propagandística de las publicaciones en tanto voceras de las facciones partidarias en pugna y, por otro, con el rol político de los medios, ya que a través de ellos la sociedad podía acercarse — de manera más directa—a los temas de la agenda pública (Duncan, 2007, p. 72).

Estos rasgos periodísticos fueron igualmente característicos de otros países latinoamericanos y europeos, y la caricatura fue uno de los ejes articuladores de su discursividad. A partir de ciertas imágenes, la prensa efectuó, de manera jocosa o apesadumbrada, una fuerte crítica social y política a través de la diferenciación, distorsión, desviación y/o exageración de los rasgos o aspectos físicos o psíquicos de los personajes retratados. Las ilustraciones, generalmente, iban acompañadas de textos humorísticos críticos a la dirigencia política que estaban en consonancia con la filiación partidaria de directores y editores (Arcas Cubero, 1996, p. 38; Matallana, 1999, pp. 22 y 25).

En términos cronológicos, el periodismo de humor político tuvo un importante desarrollo en la Argentina a lo largo del 1800. Aunque el género satírico persistió hasta los primeros años de la década del XX, comenzó a experimentar una especificidad propia que lo diferenció de las producciones decimonónicas (Román, 2010, pp. 492 y 493). Hacia la segunda mitad del siglo XIX, éste tuvo en el escenario porteño algunas de sus expresiones más significativas, como El Mosquito, Don Quijote y El Sud Americano. Debido a que en algunos tramos del artículo haremos mención a los dos primeros periódicos, creemos conveniente efectuar algunas breves consideraciones sobre ellos.

El Mosquito se publicó entre 1863 y 1893 fue dirigido, inicialmente, por el francés Enrique Meyer y luego contó con la colaboración de Enrique Stein. El periódico, a lo largo de su trayectoria editorial, se convirtió en un emblema de la crítica sagaz hacia la clase dirigente y de la prédica del "deber ser" gubernamental. Por su parte, Don Quijote tuvo una aparición más tardía (en el año 1884) y perduró diez años más respecto de su antecesor, El Mosquito. Don Quijote fue dirigido por Eduardo Sojo, un español simpatizante de las ideas del republicanismo. Durante el juarismo, fue uno de los más acérrimos denunciantes de la ilegalidad y la corrupción imperante a través de la locuacidad de sus caricaturas y su prédica política. Estos rasgos identitarios explican por qué, en más de una oportunidad, Don Quijote despertó la indignación de la clase política nacional, que no dudó en censurarlo (Matallana, 1999, pp. 52- 54, 76-79).

Cabe recordar que la popularidad que adquirió la prensa decimonónica se debe, en parte, a la emergencia de nuevos públicos lectores como consecuencia del proceso de modernización emprendido desde los poderes estatales y a la expansión del mercado editorial producto de ciertos cambios tecnológicos que posibilitaron la extensión de las redes de comunicación e intercambio (Prieto, 2006, pp. 13-14; Mauro, 2006, p. 157). 
Hacia la segunda mitad del siglo XIX, al igual que lo sucedido en el ámbito nacional, Santa Fe experimentó un importante dinamismo en lo que respecta al mundo periodístico, al menos en las ciudades más pobladas del territorio. Si bien la prensa local, en este período, siguió respondiendo a las distintas facciones políticas, surgieron otras empresas editoriales que se autodefinieron como independientes de las reyertas políticas, pese a que sus directivos fueron reconocidas personalidades del espacio partidario (Mauro, 2006, pp. 157-158). ${ }^{5}$ Quizás los ejemplos más resonantes sean los diarios rosarinos La Capital, creado en 1867 por Ovidio Lagos, referente del Partido Constitucional, y ElMunicipio, editado por primera vez en 1887 por Deolindo Muñoz, figura destacada de la Unión Cívica Radical Intransigente (Prieto, s/f, p. 4).

En la ciudad de Rosario, sólo para tener una dimensión más precisa del campo editorial, se estima que a fines de la década de 1880 existían trece empresas periodísticas, dos de las cuales se publicaban en idioma extranjero (Álvarez, 1998 [1943], pp. 388-389). Un número importante de esos periódicos pertenecían a la prensa de humor político, entre los que se destacaban Caramelo, La Cabrionera y La Bomba.

Caramelo inició su publicación en 1889 y se autodefinió como un semanario "crítico, político y de caricaturas", cuyo objetivo principal fue sostener la candidatura de Cafferata para las futuras elecciones gubernamentales en Santa Fe (Caramelo, 5/5/1889). ${ }^{6}$ Su prédica política se llevó a cabo con un lenguaje agresivo hacia sus contrincantes partidarios mediante la publicación de textos de opinión e imágenes satíricas. Entre los adversarios de Caramelo se destacaron los políticos opositores a Cafferata - como Bernardo Iturraspe- y las empresas editoriales críticas al oficialismo, como La Cabrionera y El Municipio (Cossia, 2013, p. 14).

Por su parte, La Cabrionera — cuyos inicios se remontan a 1871 - se autodenominó como un "semanario joco-serio de caricaturas" (La Cabrionera, 30/4/1871). El periódico, durante la última etapa de su vida editorial (1887-1890), debido a su posicionamiento político entró en conflicto con su par, Caramelo. Al igual que La Cabrionera, La Bomba — publicada entre 1894 y 1895, y de filiación radical- esgrimió sus críticas a las administraciones autonomistas en Santa Fe a través del uso de la caricatura y de los textos de opinión ( $L a$ Bomba, 25/5/1894). Uno de los temas que recorrió las columnas del periodismo local fueron las denuncias sobre las irregularidades en el BPSF.

\section{Los escándalos bancarios en Santa Fe durante la década del 90: emblemas de la CORRUPCIÓN}

Los manejos poco claros en la banca pública durante el juarismo, tal como lo hemos expuesto en la Introducción del presente trabajo, son una de las vías de análisis para ahondar en los escándalos de corrupción.

Antes de avanzar en nuestra exposición quisiéramos hacer algunas breves aclaraciones respecto del tema propuesto. Por un lado, con este caso no pretendemos introducirnos en las álgidas discusiones historiográficas que pivotean en torno a si la especulación y el agio pueden o no ser caratulados como causales de la crisis de 1890 . $^{7}$ Por otra parte, tampoco procuramos adentrarnos en la estricta credibilidad de cada una de las denuncias de corrupción publicadas por la prensa. ${ }^{8}$ Más bien, nos preocupa analizar los usos del término en cuestión y las ideas e imágenes que circularon en torno a él y a los personajes involucrados en los escándalos.

Cabe recordar que el BPSF fue una entidad de capitales mixtos fundada en 1874 que tenía entre sus principales accionistas al Estado provincial y a un conjunto de empresarios oriundos de las ciudades de Rosario y Santa Fe. El BPSF se constituyó en uno de los organismos crediticios más importantes de la provincia y hacia fines de la década de 1880 se incorporó a la Ley de Bancos Garantidos. Dicha normativa fue sancionada en 1887 y tuvo por objetivo reemplazar los billetes emitidos por las entidades bancarias asentadas en el país por billetes nacionales garantidos con fondos públicos. Esta decisión gubernamental se tomó para contrarrestar la escasez de circulante originada por el auge económico y el aumento demográfico 
(Martí, 1999, p. 50). ${ }^{9}$ Asimismo, la ley tuvo por fin disminuir la dependencia crediticia de las firmas provinciales respecto de las casas comerciales y bancarias asentadas en Buenos Aires (Marichal, 1988).

El sistema produjo, por un lado, la expansión de los préstamos bancarios en oro y papel moneda y, por otro, la ampliación del capital social de las entidades suscriptas, como los bancos provinciales de Córdoba, Santa Fe, Buenos Aires y Entre Ríos, que aumentaron sus emisiones monetarias. Por otra parte, y a partir de él, se crearon una multiplicidad de entidades en provincias como Santiago del Estero, La Rioja, Mendoza, San Juan, San Luis, Corrientes y Catamarca, entre otras, que comenzaron a emitir billetes. Si bien la normativa se inspiró en fines útiles, los directivos transgredieron el marco legal pues fueron partícipes o cómplices del otorgamiento de préstamos a personalidades insolventes ligadas al círculo oficial, quienes utilizaron, en gran medida, esos beneficios para fines especulativos (Marichal, 1988, p. 164; Martí, 1999, pp. 58 y 67).

Algunos de los casos más resonantes fueron las anomalías evidenciadas en el Banco Nacional (BN) y Provincia de Buenos Aires (Lotersztain, 2010). Luego de la renuncia de Juárez Celman, el Estado nacional al mando de Carlos Pellegrini (1890-1892) inició una serie de investigaciones que derivaron en causas judiciales, tal como sucedió con el BPSF. Respecto de este último, un informe final redactado por el enviado gubernamental, Ricardo Pillado, puso al descubierto que desde el BPSF se habían cometido una serie de irregularidades, entre las que se destacaban la presentación de balances dobles, la disminución significativa del encaje bancario y el otorgamiento de préstamos que excedían los montos permitidos por la normativa a personalidades vinculadas al oficialismo, muchos de los cuales se encontraban impagos (El Municipio, $25 / 10 / 1890)$.

Al focalizarnos en el modo en que la prensa retrató este tema observamos que una de las visiones que la tiñó fue la convicción de que las prácticas corruptas — que tenían como epicentro el ámbito bancarioeran una parte constitutiva de la Argentina juarista. Sobre este punto La Unión Cívica, órgano del mismo espacio político en la ciudad de Rosario, hacía referencia a que el presidente Juárez Celman era el mayor responsable de introducir el mal de la corrupción. De este modo, el término aludido era representado como una enfermedad que aquejaba al cuerpo social en su conjunto:

Si sólo se hubiera circunscripto el ex presidente Juárez, á corromper con su infamia politica, la capital de la nación, si su acción se hubiese reducido á obrar unicamente en la capital federal, dejando sin gangrenar el resto de la nación, su caída del poder hubiese devuelto la vida y la tranquilidad al pueblo argentino (La Unión Civica, 31/10/1890).

Tal como hemos hecho mención en otro de nuestros recientes escritos, esta acepción del concepto corrupción - también presente en la prensa diaria local一, entendido como degeneración social, no fue privativa del espacio periodístico sino que se encontró también presente en la prédica de los intelectuales decimonónicos pertenecientes a la corriente positivista-biologicista (Garcilazo, 2019; Terán 2000, pp. 332-333).

Sin embargo, manifestaba el periódico, pese al alejamiento político de Juárez Celman las estructuras gubernamentales corroídas aún estaban firmes. En relación con esta temática, y retomando nuevamente el parágrafo que abre este artículo, La Unión Cívica se preguntaba: "Renunció Juárez pero (...) pero quedó su sistema de gobierno (...) pero quedan sus cómplices ¿No tenemos todos los bancos de la república fundidos, porque han desaparecido sus caudales entre unos cuantos?” (La Unión Cívica, 31/10/1890).

Esa idea recurrente respecto de que las estructuras bancarias no se habían librado de sus males, luego de la crisis de 1890 , se encontraba también presente en una imagen publicada por Don Quijote. En ella se graficaba al futuro líder de la Unión Cívica Radical, Leandro Alem, con una ratonera en la mano y preparado para atrapar a los roedores que habían dilapidado los dineros bancarios (véase Figura 1). Mientras que las ratas representaban a quienes habían abusado del crédito, su cueva, es decir, el lugar en el cual se guarecían, eran las entidades bancarias. Al igual que en otras imágenes referidas a las prácticas corruptas en la segunda mitad del siglo XX, como aquella que representaba al presidente brasileño Jânio Da Silva Quadros con una escoba, en tanto símbolo de la lucha contra la corrupción, la ratonera se convertía en todo un emblema. A 
partir de su uso, el político argentino mencionado propiciaría el pasaje de un estado de guerra social —en la que imperaban las prácticas dilapidadoras- a uno de paz - producto de su desaparición- (Don Quijote, 26/10/1890; Burke, 2005, p. 77).

Figura 1: Imagen de Leandro Alem. Don Quijote, 26/10/1890

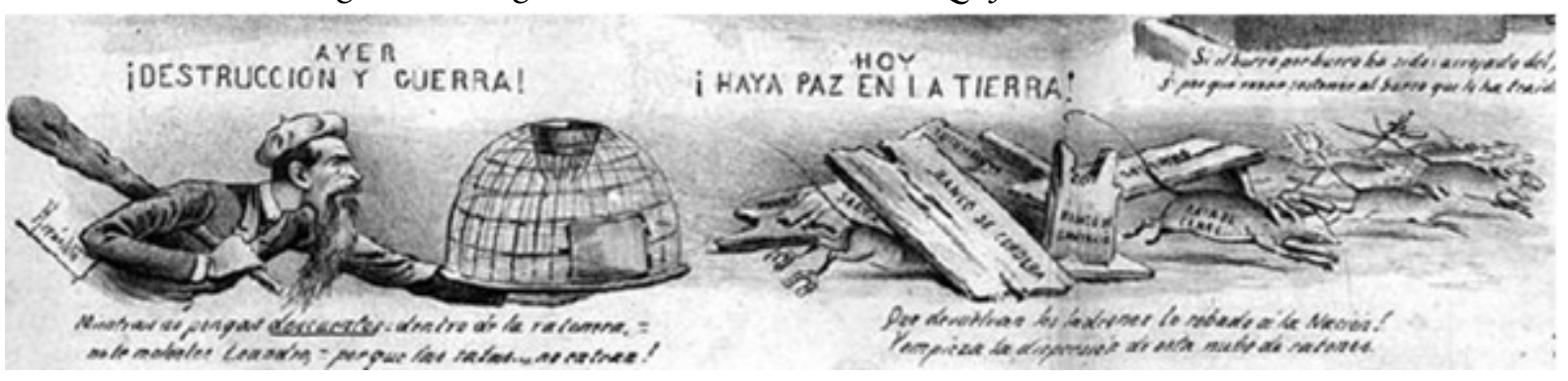

Por otra parte, observamos en el discurso periodístico la utilización del término corrupción con una connotación diferente. En una noticia publicada por Don Quijote, que refería a una manifestación cívica erigida en contra de los abusos bancarios, se expresaba:

Lo cierto es que aquel pueblo representaba la moral y la justicia y el noble ejemplo de su protesta ha sido avergonzar á más de cuatro magnates desvalijadores de bancos, que se ocultan en sus doradas viviendas, temerosos de que un día la renovación de los cuerpos colegisladores convertidos en tribunales de la nación, puedan pedirles estrecha cuenta del fruto de sus rapiñas (Don Quijote, 26/10/1890).

Con iguales términos, La Cabrionera aludía a lo acaecido en el BPSF: "La única manera de hacer mérito en ese banco y hacerse acreedor á un aumento de sueldo, es bajar al nivel del director y conquistarse la maldición de la honradez y el anatema de la moralidad" (La Cabrionera, 13/4/1890).

A partir de los fragmentos citados con anterioridad advertimos que el término corrupción se encontraba asociado a la transgresión de ciertos valores morales por parte de políticos y especuladores (Garcilazo, 2019, p. 221). Asimismo, ese discurso moralizante - característico de la prensa argentina del período e igualmente compartido por cierto periodismo abocado a los escándalos de corrupción- intentaba provocar vergüenza en quienes habían cometido actos inescrupulosos (Hirsch, 2013; Zamora y Marín Albaladejo, 2010). En aquellos años la vergüenza era una sensación contraria al honor. La atribución o asignación de este sentimiento a una persona expresaba el reconocimiento de su propio deshonor. El honor estaba vinculado a la honestidad en el desarrollo de las operaciones económicas y a la administración de los bienes públicos, entre otras acciones (Gayol, 2008, p. 239; Pitt Riviers, 1979).

No sólo Don Quijote expresó estos valores: su par El Mosquito también se refirió a esta sensación de vergüenza que imperaba en buena parte del empresariado, partícipes de los malos manejos en las entidades bancarias y ligados a los negocios estatales. La siguiente imagen publicada por El Mosquito es ilustrativa al respecto. En ella se observa la pesadumbre de un empresario encarcelado por haber pagado coimas a funcionarios estatales.

Figura 2: Empresario encarcelado. El Mosquito, 28/11/ 1890

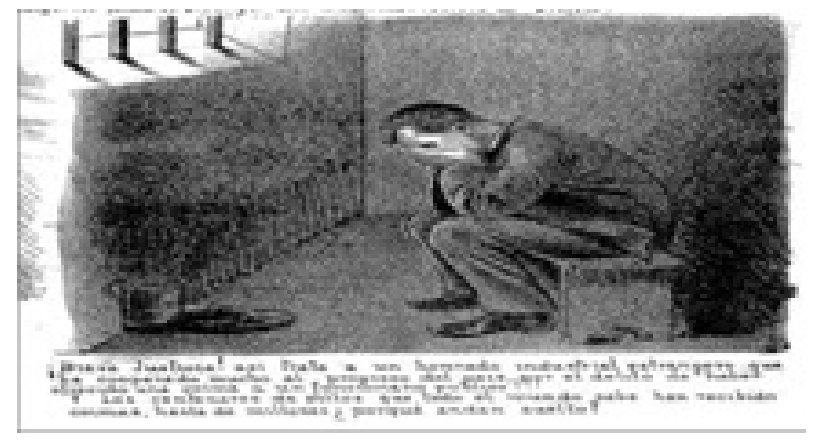


Por otra parte, las noticias sobre las irregularidades en el BPSF mostraban la contracara de este dibujo. En una nota de opinión publicada por La Cabrionera, aludiendo a los directivos de la entidad, el semanario exponía: “(...) ya van presentándose todo como lo que son: ya van arrojando las máscaras y afrontando con caras jamás enrojecidas” (La Cabrionera, 13/4/1890). Según el mencionado periódico local, a diferencia del empresario encarcelado, retratado en la Figura 2, los miembros del BPSF aún no se sentían avergonzados por su proceder.

Además, observamos en la gráfica periodística que el término corrupción estaba vinculado a sus efectos económicos. En un artículo, concerniente a la figura de Gálvez y a la situación del BPSF, se denunciaba el presunto enriquecimiento de la clase gobernante y su círculo de influencia: “(...) á vos que asesorado por las luces de potentoso cerebro; ideasteis negocios y empresas espléndidas en resultados para nuestros bolsillos" (La Cabrionera, 19/4/1890).

En consonancia con tales ideas encontramos una imagen publicada por el semanario El Mosquito, que mostraba a un niño nacido en 1889, año de opulencia, dilapidación y de derroche económico, y cuya muerte se había precipitado ese mismo año, producto de tales excesos (véase Figura 3). Aquí observamos lo dicho anteriormente, es decir, cómo el componente económico tiñó las representaciones gráficas de la corrupción. Tal como lo han mencionado otros autores, en algunos momentos las prácticas corruptas estuvieron asociadas a productos comestibles - queso, pan, torta, o plantas de higos- que simbolizaban, de algún modo, los dineros del Estado deglutidos por los integrantes del gobierno y sus amigos políticos (Matallana, 2003, p. 139; Bonaudo, 2018).

Figura 3: El principio y el fin de 1889. El Mosquito, 5 /1/ 1890

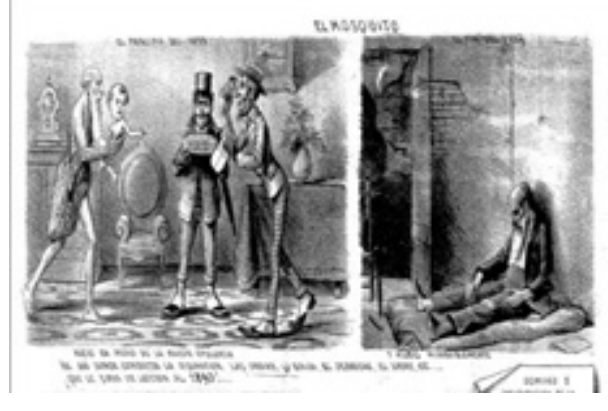

\section{DENUNCIANTES Y DENUNCIADOS: EL BPSF}

El caso del BPSF fue catalogado por la prensa local como el escándalo de los escándalos (Garcilazo, 2019). Tal denominación se debió no sólo a la magnitud de las anomalías cometidas en la entidad, sino, fundamentalmente, a la notoriedad pública de los personajes involucrados en las denuncias. No debemos perder de vista que, poco a poco, las noticias referidas al BPSF se convirtieron en escandalosas por las características propias de la prensa que se hizo eco de las irregularidades. El periodismo estaba envuelto en las disputas acaecidas en la arena político-partidaria, a la vez que pregonaba una discursividad moralizante (Hirsch, 2012). Ahora bien: ¿qué otros factores pugnaron en la construcción de las crónicas noticiosas?

Cuando analizamos las críticas entre denunciantes (prensa y grupos opositores al autonomismo) y denunciados (políticos, empresarios y banqueros) observamos que esas reyertas también encubrían fuertes intereses económicos. Para avanzar en este punto, debemos hacer algunas aclaraciones respecto del diario rosarino El Municipio, ya que fue el principal denunciante de las anomalías cometidas en el BPSF. El diario se constituyó en el núcleo de las informaciones cruzadas que circulaban sobre este tema en el ámbito periodístico. Muñoz, propietario de El Municipio, había formado parte de las filas del autonomismo provincial y se alejó de este espacio político cuando el gobernador Manuel María Zavalla (1882-1886) lo 
reemplazó en su cargo de Ministro de Gobierno por Gálvez. Luego, Muñoz se dedicó de lleno a la actividad periodística y en 1887 fundó el mencionado matutino. Desde sus columnas El Municipio se autodefinió como fiel defensor de "los intereses de la colectividad, para censurar los actos de los funcionarios públicos que no cumplan digna y honradamente con su deber" (El Municipio, 25/5/1887).

Desde fines de la década de 1880, el diario dedicó extensos editoriales a las anomalías en el BPSF, aun antes de que éstas fueran cuestionadas por otros medios gráficos (ElMunicipio, 11/09/1888). A partir de esas denuncias iniciales, el resto de la prensa local comenzó a retratar lo acaecido en la entidad construyendo un discurso focalizado en ciertas personalidades. El periodismo -al igual que en otros escándalos de corrupciónnarró los acontecimientos apelando, en algunos momentos, a la dramatización de ciertos rasgos personales de políticos, banqueros y empresarios (Zamora y Marín Albaladejo, 2010). No obstante, nos preguntamos: ¿cómo fueron representados denunciados y denunciantes por la prensa de humor político?

Para comenzar la exposición, en primer término, nos centraremos en la figura de Eloy Palacios, director del BPSF. El periodismo, tal como veremos, se refirió a Palacios no sólo a través de la palabra escrita —apelando a la ironía y al humor - sino también por medio de imágenes caricaturescas.

En un artículo aparecido en La Cabrionera, en el que se pedía públicamente que Palacios abandonase su cargo, se afirmaba: "Es preciso que renuncie Eloy (...) y es preciso porque Eloy (...) no es, no ha sido, ni será nunca lo que se llama un banquero. Y no lo será por mil distintas razones" (La Cabrionera, 13/4/1890). Tal solicitud se sustentaba en la convicción de que ese personaje carecía de las capacidades necesarias para ocupar el puesto asignado. En este sentido, La Cabrionera se preguntaba:

Es acaso un banquero, el hombre que se pone á hacer apuestas que no puede cumplir (...) y es acaso banquero, el hombre que manejando la fortuna pública (...) pone a ese banco (...) a las puertas de la tumba? (...) hay muchas condiciones que son indispensables para dirijir [sic] un banco, que Eloy no las tiene, ni las ha tenido jamás.

No es aquí cuestión de distribución de fondos ni de préstamos a personas irresponsables ni de créditos abiertos á quien no tiene tras caerse muerto ni más mérito que ser un instrumento de su señoría, no es cuestión de propiedades recibidas en pago de deudas (...) Es otra cosa más grave (...) Es el haber hecho de la historia de una institución (...) una ruin parodia de lo que es un establecimiento de su género (...) un miserable boliche (...) (La Cabrionera, 13/4/1890).

El fragmento anteriormente citado nos introduce en uno de los aspectos centrales del problema, como es la transgresión de los valores culturales de una época. A partir del texto observamos el "deber ser" al que habría faltado el banquero involucrado en las denuncias (Ruderer y Rosenmüller, 2010, p. 13; Dalamau y Burdiel, 2018, p. 18). Siguiendo las ideas de Werner Sombart (1993 [1913]) y las del periodismo, Palacios carecía de ciertos valores inscriptos en el universo burgués. Por un lado, él habría transgredido el principio de la buena administración debido a las sistemáticas irregularidades registradas en la entidad que dirigió. Por otro lado, Palacios había quebrantado uno de los comportamientos morales de la práctica empresarial, como lo era el estricto cumplimiento de las transacciones bancarias.

Asimismo, la prédica periodística fue acompañada por una serie de caricaturas publicadas por el semanario La Cabrionera, que expresaban las distintas vetas de la figura de Palacios. En algunos momentos se lo ilustró con un tinte burlesco- como una persona poderosa y violenta. En una imagen, se representó a Palacios como un personaje primitivo y monstruoso portador de un anillo, que simbolizaba el oro de la entidad (véase Figura 5). En ella se observa a Palacios haciendo un gesto burlón hacia el comercio local, que había quedado, según la información gráfica, esclavizado, víctima de los malos manejos del BPSF. Al mismo tiempo, el director del BPSF fue representado como un animal carnívoro sospechado de hacer desaparecer a los niños del territorio provincial (como se visualiza en la Figura 4). Estos rasgos atribuidos a Palacios fueron también compartidos por ciertos personajes envueltos en denuncias de corrupción en otros escenarios, como el europeo. Tal fue el caso de la reina Isabel II de España, retratada como un monstruo que, producto de sus conductas privadas, causaba aborrecimiento y menosprecio social (Burdiel, 2018, p. 41). 
Figura 4: Caricatura de Eloy Palacios. La Cabrionera, 6/10/1889

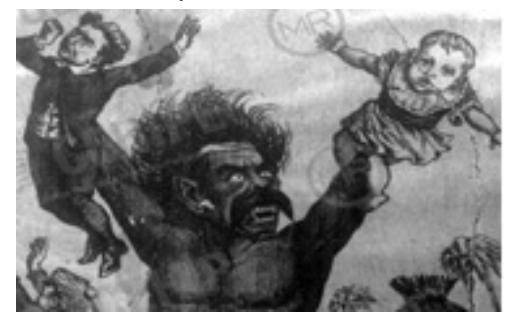

Figura 5: Caricatura de Eloy Palacios. La Cabrionera, 19/1/1890

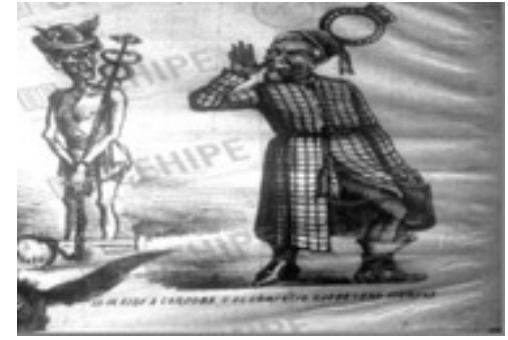

Finalmente, el análisis de estas caricaturas nos introduce en otra de las aristas del discurso periodístico, que ha sido característico de los escándalos de corrupción: la fuerte condena social (Zamora y Marín Albaladejo, 2010). Así, el director del BPSF era repudiado socialmente y castigado por la opinión pública por su mal desempeño en la entidad (obsérvese la figura 6).

Figura 6: Caricatura de Eloy Palacios. La Cabrionera, 13/4/1890

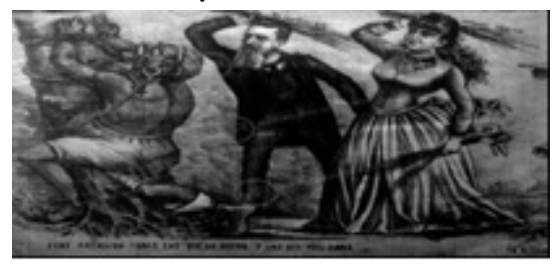

Además, esa prédica periodística condenatoria tenía como fin la recuperación del "honor de la provincia" (La Cabrionera, 13/4/1890). Creemos que esa honorabilidad, siguiendo las ideas de Sandra Gayol (2008), había sido mancillada por quienes hicieron un mal uso de los dineros públicos. Sin embargo, para recuperar ese honor, era necesaria la consecución de un bien mayor: la custodia del "crédito de la patria" ( $L a$ Bomba, 9/9/1894). Esas ideas estaban en consonancia con las banderas del radicalismo, a las que adhería el periodismo, como la defensa de la libertad, la patria, la honradez administrativa y la institucionalidad del país (El Municipio, 30/7/1893).

Por el contrario, los periódicos oficialistas construyeron una imagen muy diferente de Palacios. Caramelo, por ejemplo, destacaba la sobresaliente labor que el banquero había llevado al frente del BPSF: “(...) el primero y más sólido establecimiento de crédito con que cuenta esta provincia, quien se ha captado por su honrada administración el beneplácito y la confianza de todo el comercio Santafesino [sic]" (Caramelo, 7/4/1890). Asimismo, el semanariocalificó a Palacios como una de las figuras más ilustres del ámbito provincial, junto a Gálvez y Cafferata (Caramelo, 7/4/1890).

En segundo término, queremos recuperar las imágenes y los discursos sobre los políticos denunciados. En este sentido, el gobernador Gálvez recibió una especial atención por parte de la prensa. El dirigente fue particularmente cuestionado por haber facilitado las anomalías acaecidas en el BPSF y por enriquecerse con 
tales prácticas. Respecto de este tema, un texto referido a la figura del gobernante ponía en duda sus cualidades para la función pública:

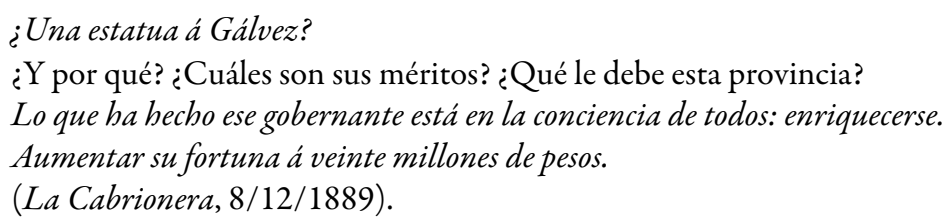

Aquí, el periódico criticaba al gobernador por acrecentar su fortuna personal. Este rasgo ponía en tensión el "deber" político de Gálvez, en tanto que, con sus acciones, había colocado sus intereses particulares sobre el bien común (Escalante Gonzalbo, 1992, p. 51).

Por otra parte, el político era denunciado por alentar las prácticas especulativas y las irregularidades en la asignación de créditos en el BPSF. Ellas habían coadyuvado al cuadro de corrupción general. Sobre este punto, la prensa aseveraba: "Lo que ha hecho ese gobernante (...) [es] soltar sobre la Provincia una verdadera avalancha de lobos hambrientos que la devoren (...) Empeñar el crédito de la Provincia al estremo [sic]" ( $\mathrm{La}$ Cabrionera, 8/12/1889). Además, se cuestionaba a Gálvez por estar rodeado de seguidores que, fruto de esos beneficios particulares, se habían convertido en personas corrompidas e ignorantes de las virtudes que todo buen gobernante debía imitar - como la honradez administrativa y el respeto en el manejo de los dineros públicos-(La Cabrionera, 8/12/1889).

Según la prensa opositora, esos rasgos del político no eran privativos de él, sino característicos de la clase dirigente nacional y provincial. Sobre este aspecto, La Bomba manifestaba:

Gálvez ha sido un coimero

Y Juárez otro que tal (...) Roca una calamidad

(La Bomba, 16/09/1894).

Más aún, la personalidad de Gálvez se erigía como representativa de los sectores políticos objetados por la transparencia administrativa. Así lo sugiere una caricatura editada por el semanario El Mosquito en la que se mostraba a los gobernadores de Santa Fe - José Gálvez - y Buenos Aires - Máximo Paz - siendo castigados y obligados a aprender a "no despilfarrar los dineros públicos" (El Mosquito, 6/4/1890).

Figura 7: Caricatura de José Gálvez. El Mosquito, 6/4/1890

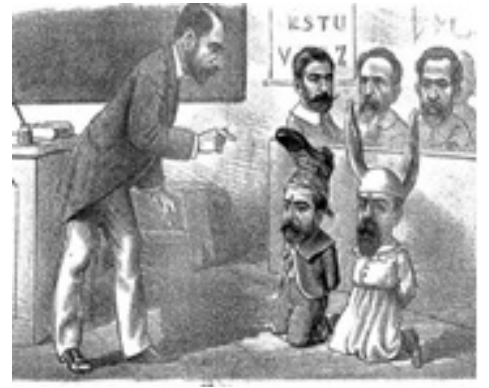

Para finalizar, quisiéramos esbozar algunas reflexiones respecto de Gálvez que se desprenden de la comparación con otras caricaturas de personalidades políticas. En las ilustraciones del periodismo porteño, al igual que otros referentes del autonomismo sospechados de corrupción —como Juárez Celman, representado en más de una oportunidad con orejas de burro y bolsas de dinero en sus manos-, la figura de Gálvez fue deformada colocándosele elementos o frases que lo identificaban con la mala administración y el enriquecimiento personal —véase figura 7-(Dell'Acqua, 1960, pp. 62-63). Por otro lado, la prensa rosarina publicó textos de opinión que ponían en duda — de manera sagaz - las cualidades políticas del gobernador pero las caricaturas divulgadas, tanto por el periodismo opositor como oficialista, no parodiaban su figura. 
Este rasgo las diferencia de las representaciones que se hicieron de políticos nacionales graficados como animales - Juárez Celman representado como un burro y Roca como un zorro- o personajes grotescos Marcos Juárez, hermano del presidente, fue dibujado como un gaucho violento- (Caramelo, 9/3/1890; La Cabrionera, 2/2/1890; Román, 2010, p. 377).

En tercer lugar, queremos recuperar las representaciones que se hicieron de otros personajes involucrados en las denuncias de corrupción: los empresarios. Debido a que hemos hecho mención a ello en otro de nuestros trabajos recientes, sólo esbozaremos algunas breves consideraciones. Aquí nos focalizaremos en Juan Canals, uno de los hombres de negocios más representativos de la gestión galvista que, en más de una oportunidad, fue cuestionado, en su rol de contratista, por las irregularidades en el desarrollo de la obra pública local y por haberse beneficiado, gracias a sus influencias políticas, con un importante crédito en el BPSF (Garcilazo, 2013, 2017a, 2017b).

En algunos momentos, el periodismo opositor retrató a Canals como una persona tramposa que se había enriquecido con los dineros públicos. En una caricatura publicada por La Cabrionera, se mostraba al contratista haciendo un gesto burlón a la sociedad rosarina y con una maleta llena de dinero — similar a la Figura 5 referida a Palacios- (La Cabrionera, 22/12/1889). Por otra parte, tanto en los textos escritos como en las caricaturas, Canals fue representado como un tiburón depredador de los dineros del Estado (Garcilazo, 2017b, p. 187). Sobre este tema, un semanario local exclamaba: "Tiburón! Tiburón! Cada peso que de ese modo introduces en tu bolsillo y (...) en el de otros implica una maldición que el verdadero pueblo santafecino [sic], ese pueblo (...) formula contra ti y los demás que en estas explotaciones inicuas te acompañan" ( $L a$ Cabrionera, 22/12/1889).

Por todo lo expuesto, podemos afirmar que la figura del empresario fue reconstruida a partir de una discursividad periodística que colocaba el foco en las consecuencias económicas que las prácticas desleales ocasionaban al conjunto social (Zamora y Marín Albaladejo, 2010).

Finalmente, creemos oportuno centrarnos en las representaciones que desde la prensa se esbozaron en torno a Muñoz, principal denunciante de las irregularidades en el BPSF. Sin duda, la fuerte prédica anti galvista de El Municipio encontró en los acontecimientos del BPSF uno de los puntos más eficaces para desprestigiar la gestión del gobernador. Esas intencionalidades, tal como hemos dicho, estaban en consonancia con el posicionamiento político de Muñoz y con la identidad periodística propia de $E l$ Municipio. En un artículo publicado en el semanario porteño El Mosquito se calificaba a Muñoz y a su diario como baluartes de la prensa denuncialista cuya acción trascendía la esfera local:

Es que El Municipio como entidad moral es obra exclusiva de Muñoz, asi como su progreso material se debe al pueblo, su propietario le ha impreso su carácter, su patriotismo y honradez (...) eso explica su sorprendente popularidad, el fenómeno de su desarrollo único en el periodismo argentino por lo rápido y único en el periodismo de provincia (El Mosquito, 26/5/1889).

La prensa de humor, tanto adepta como opositora a Gálvez, construyó una discursividad en torno a los escándalos de corrupción que tuvieron como protagonista a Muñoz. Para algunos periódicos, el director de El Municipio representaba al periodismo honrado defensor de la buena administración gubernamental, mientras que, para otros, él era un hombre infame portador de los males morales que decía combatir. En este sentido, es interesante destacar que el director fue criticado, más que por su posicionamiento político, por estar involucrado en emprendimientos económicos poco honorables. En varias oportunidades, se cuestionó a Muñoz por haber participado en el negocio de la lotería. Sobre este tema, Caramelo afirmaba:

Deolindo Muñoz, el ex lotero y tal vez sin el ex, dice día á [sic] día, que nuestro jefe político es un déspota que obra á [sic] su antojo sin que haya ley que ponga freno á [sic] sus desmanes.

Para obrar asi el jefe politico, y no dar lugar á [sic] que mienta el director de El Municipio, cosa de que debe avergonzarse mucho Muñoz y ver si en su casa se encuentran billetes de lotería de la Rioja, San Luis, etc. (Caramelo, 20/10/1889). 
Para reforzar esta idea, Caramelo identificó a Muñoz como un personaje dedicado al juego, más específicamente, al toreo (véase figura 8).

Figura 8: Caricatura de Deolindo Muñoz. Caramelo, 12/1/1890

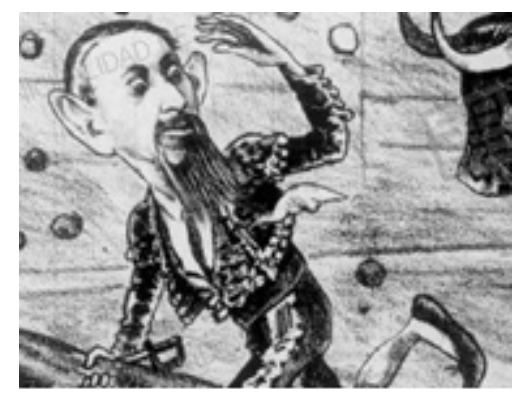

Asimismo, Muñoz fue representado por sus detractores como un hombre interesado, exclusivamente, en la actividad lucrativa y preocupado por ocupar un puesto político. Según la prensa oficialista, toda la prédica denuncialista del director de El Municipio encubría tales fines. Sobre este tema, Caramelo exclamaba:

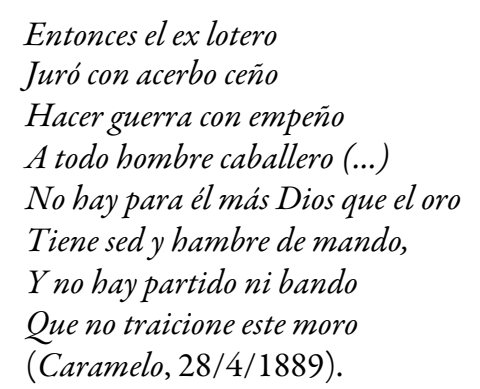

Según cierta prensa, la sagacidad de los comentarios de Muñoz sobre las anomalías en el BPSF parecía estar en consonancia con las lógicas de la disputa interbancaria. El periodista fue cuestionado por su participación en el BN y, fundamentalmente, por ser uno de sus deudores. Las denuncias cruzadas entre Muñoz y el oficialismo respecto de su actuación en esta esfera económica se fueron recrudeciendo en un momento clave. En medio de las graves críticas al BPSF, en 1889 se dio a conocer que el BN, con sede en la ciudad de Rosario, había solicitado autorización para aumentar su capital social. Cabe recordar que el BN, hacia fines de la década de 1880 , poseía un capital sustancialmente menor -800.000 pesos $\mathrm{m} / \mathrm{n}$ - que el del BPSF -5.000 .000$ pesos m/n- (Carrasco, 1886, p. 489). En relación con ese pedido Muñoz arengó, desde las columnas de $E l$ Municipio, sobre la necesidad de que la solicitud bancaria fuera aprobada. Uno de sus argumentos más sólidos fue que, dada la imposibilidad crediticia que en ese momento tenían entidades como el BPSF, debido a sus malos manejos, era vital para el comercio rosarino que otras instituciones como el BN ampliaran sus servicios (El Municipio, 24/11/1889).

Tales dichos generaron la sospecha de Caramelo, que no dudó en acusar a Muñoz de pretender acrecentar - a través de su desprestigio al BPSF-, con tales estrategias, la credibilidad financiera de otras casas como el BN. Sobre este tema, el periódico afirmaba:

Don Oliendo (...) no debería insultar y calumniar al Banco Provincial.

Dice con esa desfachatez que nadie niega (...) que el Banco Provincial ha cerrado sus puertas al comercio.

Miente.

A quien ha cerrado sus puertas el Banco Provincial,

Es a las ratas, rufianes (...) Porque en el Banco Provincial no se abren créditos para no pagarlos, como se hace en el Banco

NacioMal [sic], sin que se haya animado á desmentirlo ese consejero infame que cree que arrojando barro sobre el caballero que está al frente del Banco Provincial,

Logrará borrar la mala impresión, que ha causado en el comercio la grave denuncia hecha contra el Banco NacioMal [sic] (Caramelo, 1/12/ 1889). 
Por otra parte, y tal como se desprende de la noticia anterior, Caramelo, bajo el rótulo de Banco Nacio(Mal), hacía alusión a que las mismas irregularidades que desde la prensa opositora causaban la indignación frente a lo acaecido en el BPSF eran también características de esa casa bancaria, de la cual Muñoz era partícipe.

\section{CONSIDERACIONES FINALES}

A partir del caso analizado hemos ahondado en la importancia de los espacios bancarios provinciales, en tanto engranajes político- empresariales donde se suscitaron prácticas catalogadas como corruptas por parte de la opinión pública. Poco a poco, y en consonancia con lo acaecido a nivel nacional, hacia fines del siglo XIX las irregularidades evidenciadas en el BPSF causaron una fuerte indignación social y se convirtieron en motivo de debate en el espacio noticioso, como ejemplificación de las anomalías administrativas características de las gestiones autonomistas en Santa Fe durante ese período. Así, y al calor de la multiplicidad y sistematicidad de la información publicada por la prensa de humor político, las denuncias cruzadas sobre lo acontecido en el BPSF pivotearon en torno a las diversas concepciones de la idea de corrupción y de las características atribuidas a los personajes involucrados en aquellas.

Respecto al primero de esos puntos, hemos observado que el término corrupción fue utilizado para hacer referencia a la degeneración o enfermedad que había afectado a la sociedad en su conjunto. En este sentido, y tal como lo sugieren las imágenes analizadas, el combate contra este flagelo llevaría al retorno de un estado de paz. Asimismo, el concepto hacía alusión a la transgresión de ciertos valores morales llevada a cabo tanto por políticos como por personalidades ligadas al mundo de los negocios. A diferencia de la discursividad presente en la prensa diaria local referida a la temática — que destacó la ilegalidad de las prácticas descriptas—, el periodismo de humor apeló más bien a enfatizar las acciones indignas de los denunciados por haber faltado a su "deber ser" (Garcilazo, 2019). Sobre estas concepciones se esbozaron ciertas imágenes periodísticas que retrataban tanto a denunciados como a denunciantes. Para lograr tal efecto las publicaciones periódicas apelaron a la ironía, al sarcasmo y a la gráfica de los personajes en cuestión, que en algunos casos fueron retratados con rasgos monstruosos - los ejemplos más emblemáticos fueron los de Canals y Palacios- y en otros, exagerando sus conductas indignas — como las caricaturas referidas a Gálvez y a Muñoz-.

Pese a sus diferencias y particularidades, todas las representaciones, tanto de acusados como de acusadores, deben ser entendidas a la luz de las disputas acaecidas en el plano político, pero también en el económico. Esto último nos lleva a destacar, tal como se ha dicho, que buena parte de la prédica periodística — que construyó su relato a través del enfrentamiento de los personajes involucrados en las denuncias- intentó generar indignación social entre su público lector enfatizando los efectos o las consecuencias económicas de las prácticas indignas. Por eso, los actores fueron referenciados con acciones ligadas al robo, al pillaje, a los negocios ilegales y al enriquecimiento rápido.

\section{Agradecimientos}

La autora agradece a los coordinadores del presente dossier por la invitación a participar de este espacio, como también a los evaluadores anónimos del Anuario del Instituto de Historia Argentina. Asimismo, fue de vital importancia para la elaboración del presente trabajo contar con la lectura atenta de la Dra. Marta Bonaudo y de la Lic. Laura Badaloni. 


\section{DOCUMENTACIÓN PRIMARIA IMPRESA}

Carrasco, G. (1886). Descripción geográfica y estadistica de la provincia de Santa Fe. Buenos Aires: Impresión, litografía y encuadernación de Stiller y Laass.

\section{Publicaciones Periódicas}

Caramelo, 1889

Don Quijote, 1890

El Mosquito, 1889, 1890

El Municipio, 1887,1888, 1890, 1893

La Bomba, 1894

La Cabrionera, 1871, 1889, 1890

La Unión Cívica, 1890

\section{Bibliografía}

Alonso, P. (2010). Jardines secretos, legitimaciones públicas. El Partido Autonomista Nacional y la política argentina de fines del siglo XIX. Buenos Aires: Edhasa.

Alonso, P. (comp.) (2004). Construcciones impresas. Panfletos, diarios y revistas en la formación de los Estados Nacionales en América Latina, 1820-1920. Buenos Aires: Fondo de Cultura Económica.

Álvarez, J. (1998) [1943]. Historia de Rosario (1869-1939). Rosario: UNR Editora-Editorial Municipal de Rosario.

Arcas Cubero, F. (1996). La imagen antes de la fotografía: grabado, pintura y caricatura de prensa en el siglo XIX. Ayer, (24), 25-39.

Bonaudo, M. (2018). 1887/1893 ¿Un umbral en el "bilo rojo" de la percepción de la corrupción política? (Inédito).

Bonaudo, M. (2005). Vecinos, Contribuyentes y Ciudadanos entre la representación de intereses y el interés general. Revista de Historia, (10), 25-58.

Burdiel, I. (2018). La revolución del pudor: escándalos, géneros y política en la crisis de la monarquía liberal en España. Historia y Politica, (39), 23-51.

Burke, P. (2005). Visto y no visto. El uso de la imagen como documento histórico. Barcelona: Crítica.

Campazas, A. (1987). Historia del Banco Provincial de Santa Fe. Santa Fe: s/d.

Cossia, L. (2013). Sobre usos y funciones de la sátira- política gráfica. (Rosario 1871-1890). Chasqui, (21), 10-16.

Dalmau, P. y Burdiel, I (2018). La imagen pública del poder. Escándalos y causas célebres en Europa (siglo XIX-XX). Presentación. Historia y Política, (39), 17-22.

De Marco, M. (2002). El contralor del Estado en la transformación argentina. Tierras, ferrocarriles y obras públicas en Santa Fe. Temas de Historia Argentina y Americana, (1), 15-63.

Dell'Acqua, A. (1960). La caricatura política argentina. Buenos Aires: Eudeba.

Duncan, T. (1981). Government by Audacity. Politics and the Argentine Economy 1885-1892 (Tesis). Universidad de Melbourne, Melbourne, Australia.

Duncan, T. (2007). La prensa política. Sud-América 1884-1892. Revista de Instituciones, Ideas y Mercados, (46), 65-92.

Engels, I. (2017). Corruption and Anticorruption in the Era of Modernity and Beyond (inédito).

Escalante Gonzalbo, F. (1992). Ciudadanos imaginarios. México: El Colegio de México.

Garcilazo, R. (2013). Un tema conflictivo: la propuesta de Juan Canals para la construcción de tabladas, mataderos y mercados de abasto. Rosario, 1889. Secuencia, (86), 113-135. 
Garcilazo, R. (2017a). El empresariado de la obra pública y los grupos políticos durante el galvismo. Santa Fe (Argentina), segunda mitad del siglo XIX. América Latina en la Historia Económica, 24(2), 125-147.

Garcilazo, R. (2017b.). El universo burgués tensionado por la honra, la deshonra y la honorabilidad. El caso de Juan Canals, Rosario (Santa Fe, Argentina), segunda mitad del siglo XIX. Historia y Sociedad, (33), 167-200.

Garcilazo, R. (2019). Los escándalos de corrupción retratados por la prensa. El caso del Banco Provincial de Santa Fe (Argentina), durante la segunda mitad del siglo XIX. Anuario Colombiano de Historia Social y de la Cultura, (26), 209-230.

Gayol, S. (2008). Honor y duelo en la Argentina moderna. Buenos Aires: Siglo Veintiuno.

Gerchunoff, P., Rocchi, F. y Rossi, G. (2008). Desorden y progreso. Las crisis económicas argentinas 1870-1905. Buenos Aires: Edhasa.

Giordano, V. (2000). La corrupción política en Argentina 1886-1890. Una mirada desde The Times de Londres. Sociohistórica (7), 251-268. Recuperado de http://www.memoria.fahce.unlp.edu.ar/library?a $=\mathrm{d} \& \mathrm{c}=\mathrm{arti} \& \mathrm{~d}=\mathrm{Jp}$ r2828

Giordano, V. (2003). Qué va cha ché. Corrupción y poder político en la Argentina 1890 cien años después (Tesis de Maestría). Universidad Nacional de Buenos Aires. Facultad de Ciencias Sociales, Buenos Aires, Argentina. Recuperado de http://www.catedras.fsoc.uba.ar/udishal/art/que_va_cha_che.pdf

Hirsch, L. (2012). Entre la "movilización” y la "evolución”. Las movilizaciones del 90. Polhis, 9. Recuperado de http: //archivo.polhis.com.ar/datos/Polhis9_HIRSCH_DOSSIER.pdf

Hirsch, L. (2013). Prensa independiente y crítica moral al juarismo (1889-1890). Estudios Sociales, (44), 73-100.

Jiménez Sánchez, F. (1995). Detrás del escándalo político. Opinión pública, dinero y poder en la España del siglo XX. Barcelona: Tusquets Ediciones.

Jiménez Sánchez, F. (1997). Posibilidades y límites del escándalo político como forma de control social. En F. Laporta y S. Álvarez (Eds.), La corrupción política (pp. 39-71). Madrid: Alianza Editorial.

Laporta, F. (1997). La corrupción política: introducción general. En F. Laporta y S. Álvarez (Eds.), La corrupción politica (pp. 293-334). Madrid: Alianza Editorial.

Little, W. y Posada Carbó, E. (1996). Political corruption en Eurepe and Latin America. Basingstoke, United Kingdom: Intitute of Latins Americans Studies University of London.

Lotersztain, I. (2010). Los bancos se roban con firmas. Corrupción y crisis en 1890. Buenos Aires: Turmalina.

Malem Seña, J. (1997). El fenómeno de corrupción. En F. Laporta y S. Álvarez (Eds.), La corrupción política (pp. 71-90). Madrid: Alianza Editorial.

Marichal, C. (1988). Historia de la deuda externa en América Latina. México: Alianza Editorial Mexicana.

Martí, G. (1999). El sistema bancario en vísperas de la crisis de 1890. Una revisión crítica de su incidencia en la política económica de Juárez Celman, 1887-1889. Ciclos, 7(17), 47-83.

Martirén, J.L. (2016). La transformación farmer. Colonización agricola y crecimiento económico en la provincia de Santa Fe durante la segunda mitad del siglo XIX. Buenos Aires: Prometeo-Asociación Argentina de Historia Económica.

Matallana, A. (1999). Humor y politica. Un estudio comparativo de tres publicaciones de humor politico. Buenos Aires: Eudeba.

Matallana, A. (2003). El 90. La crisis económica y política vista desde la gráfica satírica de la época. Temas de Historia Argentina y Americana, (3), 131-143.

Mauro, D. (2006). De la prensa de círculo a los albores de la prensa comercial. En M. Bonaudo (Dir.). La organización productiva y politica del territorio provincial (1853-1912) (pp. 149-168). Rosario: Prohistoria-La Capital.

Monier, F., Dard, O. y Engels, I (2014). Patronage et corruption politiques dans l'Europa Contemporaine (Vol. II). París: Armand Colin.

Pitt Riviers, J. (1979). Antropología del honor o politica de los sexos. Barcelona: Crítica.

Prieto, A. (2006). El discurso criollista en la formación de la Argentina moderna. Buenos Aires: Siglo Veintiuno Editores. 
Prieto, A. (s/f). La revolución radical de 1905 en Rosario ¿Conspiración Cívico-Militar o revolución del pueblo?. Recuperado de http://www.historiapolitica.com/datos/biblioteca/Prieto.pdf

Robotnikof, N. (1999). Corrupción política: definiciones técnicas y sentidos sedimentados. Revista Teoría y Filosofía del Derecho, (10), 25-39.

Rojking, I. (2012). "La revolución está vencida, pero el gobierno ha muerto". La crisis política, discursos periodísticos y demostraciones callejeras en Buenos Aires, 1890. Anuario de Estudios Americanos,69(2), 507-532.

Román, C. (2010). La prensa satírica argentina del siglo XIX: palabras e imágenes (Tesis Doctoral). Universidad Nacional de Buenos Aires. Facultad de Filosofía y Letras, Buenos Aires, Argentina. Recuperado de http://repo sitorio.filo.uba.ar/handle/filodigital/1613.

Rosenmüller, C. y Ruderer, S. (2016). Dádivas, dones y dineros. Aportes a una nueva historia de la corrupción en América Latina desde el imperio español a la modernidad. Madrid: Instituto Ibero-Americano.

Sombart, W. (1993) [1913]. El burgués. Contribución a la historia espiritual del hombre económico moderno. Madrid: Alianza Editorial.

Szir, S. (2011). El semanario popular ilustrado Caras y Caretas y las transformaciones del paisaje cultural de la modernidad. Buenos Aires 1898-1908 (Tesis doctoral). Universidad Nacional de Buenos Aires. Facultad de Filosofía y Letras, Buenos Aires, Argentina. Recuperado de http://www.repositorio.filo.uba.ar/handle/filodigi $\mathrm{tal} / 1886$.

Szir, S. (2014). El Sud Americano. Notas para una historia material y visual de la prensa periódica ilustrada en el siglo XIX. En V.Delgado, A. Mailhe y G. Rogers (Coords.), Tramas impresas. Publicacionesperiódicas argentinas (XIX$X X)$ (pp. 80-96). La Plata: Universidad Nacional de La Plata.

Terán, O. (2000). El pensamiento finisecular (1880-1916). En M. Lobato (Dir.), Nueva Historia Argentina (Vol. 5 , pp. 327-363). Buenos Aires: Sudamericana.

Thompson, J. (2001). El escándalo politico: poder y visibilidad en la era de los medios. Barcelona: Paidós Ibérica.

Zamora, R. y Marín Albaladejo J. A. (2010). La representación simbólica del escándalo político. Hacia una tipología de los marcos periodísticos (frames) utilizados en la narración de los escándalos de corrupción política. Razón y Palabras, (73). Recuperado de http://razonypalabra.org.mx/N/N73/Varia73/34ZamoraMarin_V73.pdf

\section{Notas}

1 Hacia fines de la década de 1880, y en consonancia con las denuncias sobre las irregularidades en la mayoría de las entidades bancarias del país, la opinión pública se hizo eco de lo acaecido en el BPSF. Posteriormente, el tema fue una constante luego de la caída del régimen juarista y adquirió mayor notoriedad en 1894, cuando en el seno del Parlamento Nacional se convirtió en motivo de acalorados debates (Garcilazo, 2019).

2 Cabe recordar que esta vertiente tiene por fin trascender el estudio de las prácticas corruptas para focalizarse en, al menos, tres problemas: el análisis del término corrupción, el contexto en el cual éste se desarrolla y el uso político de las denuncias (Rosenmüller y Ruderer, 2016).

3 Siguiendo el pensamiento de Andrea Matallana (1999), definimos bajo este rótulo un tipo de prensa que utilizó el humor político como un elemento de crítica social.

4 Cabe recordar que el Autonomismo fue el partido hegemónico y de gobierno liderado por Julio A. Roca. Este espacio fue caracterizado por Paula Alonso (2010, p. 16) como un conjunto de ligas en clara disputa por la competencia presidencial.

5 Durante la década de 1880 el Autonomismo disputó la arena electoral provincial con otros espacios que bregaban por una política más inclusiva, como, por ejemplo, el Partido Constitucional (1883-1886).

6 Cafferata gobernó Santa Fe durante el período 1890-1893, representando al partido Autonomista, también llamado Situacionista o Partido del Pueblo.

7 Sobre este tipo de discusiones, véase Martí, 1999, pp. 48-49.

8 Las irregularidades en el BPSF quedaron asentadas en un informe presentado por el agente gubernamental, Ricardo Pillado. El mismo derivó en una denuncia de defraudación remitida a los Tribunales Federales de la ciudad de Rosario (Campazas, 1987).

9 Acerca de la discusión que generó la aplicación de la Ley de Bancos Garantidos en el ámbito legislativo nacional, véase Gerchunoff, Rocchi y Rossi, 2008, pp. 82-88. 